\title{
DONALD TRUMP Y CAMBIO CLIMÁTICO
}

\author{
Evangelina Dardati,
}

Académica FEN UAH PhD en Economía, Universidad de Texas en Austin

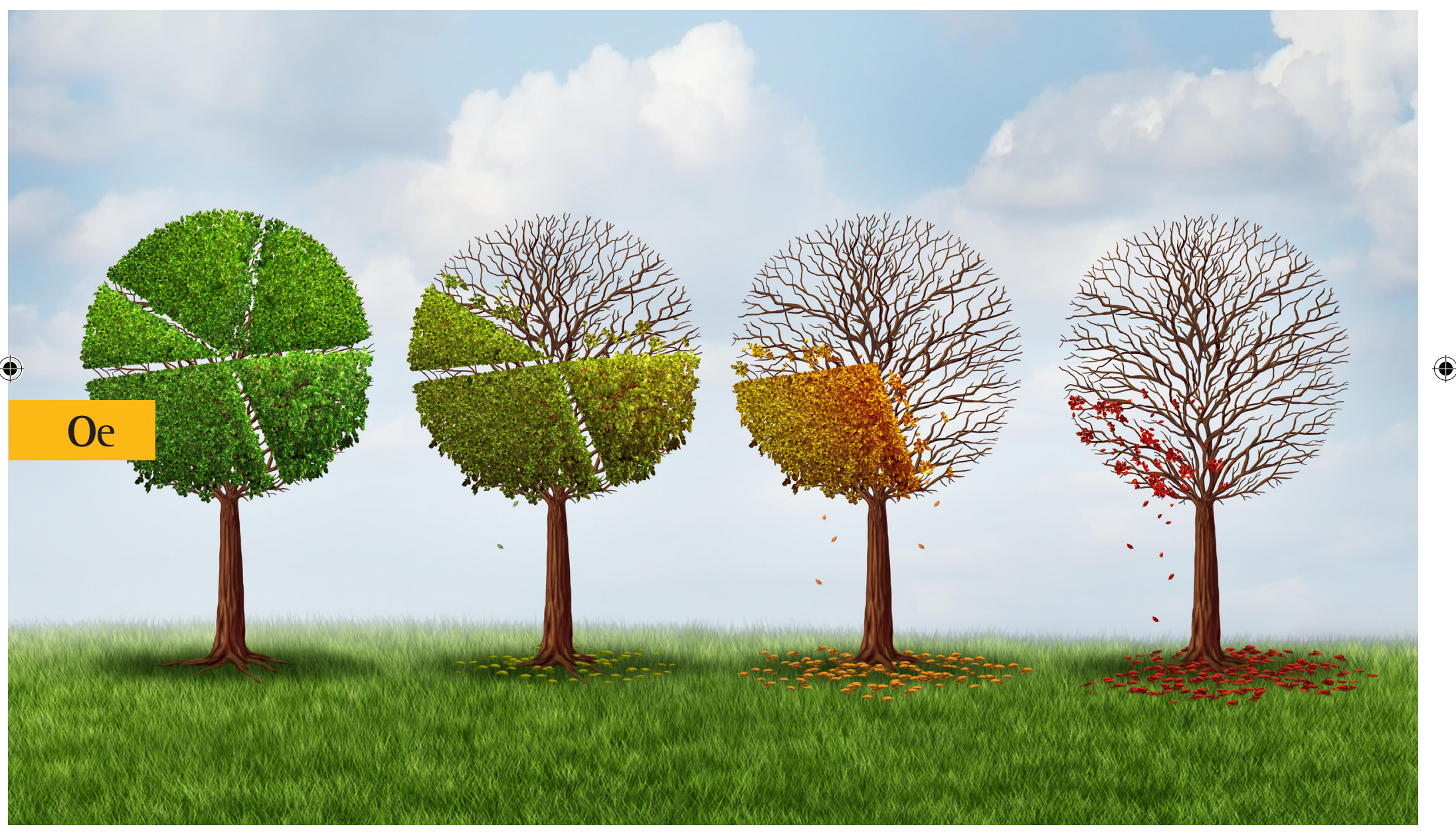

Hace exactamente un año se firmaba el acuerdo de París en el que se consensuó limitar el aumento de la temperatura global a menos de 2 grados con respecto a los niveles preindustriales. En total, 186 paises responsables de 96\% de las emisiones globales entregaron metas de reducción de GEI. Hoy, 117 de ellos han ratificado dicho acuerdo (lo que corresponde a un 66\% de las emisiones globales).El resto, tiene plazo hasta abril de 2017 para hacerlo. Estados Unidos, uno de los principales emisores de $\mathrm{CO}$, buscó bajo la administración de Obama posicionarse como líder en la lucha contra el cambio climático, objetivo que ahora está en duda con la llegada de Donald Trump al poder.

Motivos para preocuparse hay. Como hemos señalado en artículos anteriores (ver ediciones anteriores de OE en http://fen. uahurtado.cl/seccion/noticias/publicaciones/), dada la naturaleza de "mal público" del cambio climático, los países tienen incentivos a ser "free-riders" en la lucha contra el mismo, apoderándose de 
sus beneficios pero no pagando los costos. Por otra parte, durante toda su campaña, Donald Trump se mostró en contra de políticas para reducir las emisiones de gases de efecto invernadero. De hecho alguna vez twitteó que el cambio climático era una invención de China para que Estados Unidos se volviera menos competitivo. También, durante su campaña, dijo que iba a cancelar la participación de EE.UU en los acuerdos internacionales, y que iba a abandonar el "Clean Power Plan" (el ambicioso plan de la administración de Obama para reducir las emisiones de gases de efecto invernadero de las generadoras eléctricas en 32\% para el 2030). Consistente con estos dichos, en los últimos dias Trump nombró a Scott Pruitt para que dirija la EPA (Agencia de Protección Ambiental), quien no solo es un escéptico del cambio climático sino que está ligado a firmas de gas y carbón y en al pasado litigó contra la EPA.

Ahora bien, ¿cómo es la situación en el resto del mundo? Hasta hace un año China se negaba a tomar alguna política activa poniendo como excusa que Estados Unidos no lo hacía. En la reunión de París, hace un año, ambos paises se comprometieron a luchar contra el cambio climático. Ahora, no sabemos si Estados Unidos finalmente hará algo y surgen las dudas con China: ¿qué hará el gigante asiático? ¿Implica esto que no habrá acuerdo ni políticas para los próximos años?

Evidentemente Estados Unidos no será el líder en la lucha contra el cambio climático. Sin embargo, hay varias razones por las cuales creemos que los objetivos pactados seguirán su curso, participe o no de forma activa.. Por empezar, el cambio climático es un tema de largo plazo, muchas compañias grandes ya planean un futuro en donde será costoso contaminar. Según un artículo publicado en Bloomberg, 60\% de las 100 compañias en Fortune tienen planes para obtener gran parte de su energía de fuentes renovables. Por lo tanto, una administración de 4 u 8 años que no crea en la regulación del medio ambiente, no debiera cambiar el proceso en que las firmas saben que deben adaptarse a un futuro en donde el cambio climático estará en la agenda de la mayoría de los países. Cabe destacar también que muchos estados en EE.UU. implementaron políticas de promoción de energías renovables. California tiene desde 2013 un sistema de permisos transables para regular los gases de efecto invernadero. Estas políticas probablemente continuarán, independientemente de la nueva administración.
En el siguiente gráfico podemos observar cuánto representan las emisiones de $\mathrm{CO} 2$ de países seleccionados en las emisiones totales del mundo. China emite casi 30\% del total global, Estados Unidos 15\% y Europa 10\% aproximadamente. Es decir, lo que hagan China y Europa frente a este nuevo escenario global es fundamental. Europa fue desde siempre el más preocupado por las crecientes emisiones de $\mathrm{CO} 2$ y una negativa de Estados Unidos a cumplir con los acuerdos no creemos que cambie esta situación. En cuanto a China, la situación es más complicada. Si bien este país siempre fue el más reticente a implementar cualquier política para atacar la contaminación, esta situación ha cambiado. Las ciudades chinas están dentro de las más contaminadas del mundo y en los últimos dos años, el Gobierno empezó a mostrar una gran preocupación por mejorar la calidad del aire. En efecto, China planea incrementar fuertemente la capacidad de energía solar en los próximos años junto con invertir para abaratar los costos de la misma.

Por tanto, si bien Donald Trump supone un riesgo importante para la incipiente lucha contra el aumento de la temperatura global, la institucionalidad que ya tomó el problema del cambio climático parece ser demasiado fuerte para que un presidente pueda lograr desarmarla. Probablemente Estados Unidos ya no lidere este movimiento, al menos por unos años. Y aunque esto pudo haber sido impensado hace algún tiempo atrás, quizás China aflore como el nuevo líder global en este ámbito, seguido por Europa.

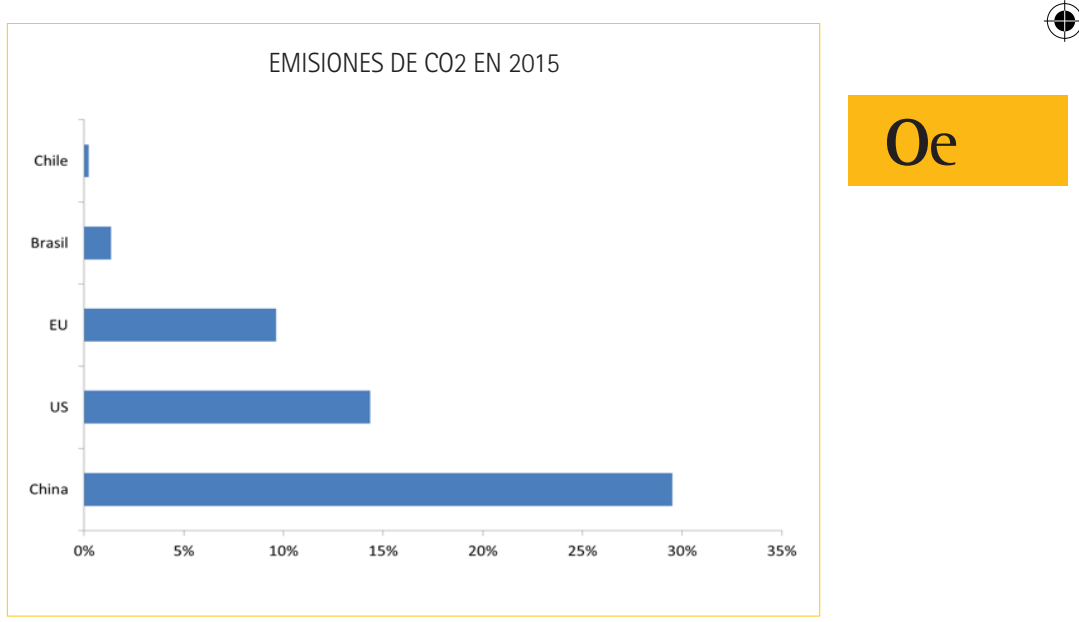

